\title{
RETRACTED ARTICLE: Prediction of maximal oxygen uptake from ratings of perceived exertion and heart rate during running: the effect of age
}

James Faulkner • Danielle Lambrick

Accepted: 23 May 2010/Published online: 10 June 2010

(C) Springer-Verlag 2010

This article has been retracted due to copyright issues that cannot be resolved.

J. Faulkner $(\square)$

Institute of Food, Nutrition and Human Health,

Massey University, Private Bag 756,

Wellington 6140, New Zealand

e-mail: J.Faulkner@massey.ac.nz

D. Lambrick

School of Sport and Health Sciences,

University of Exeter, Exeter, UK 